\section{"A Terrorist Incident"}

Major D J Vassallo

FRCS (Ed), RAMC, Surgical Specialist

Major B R Singer

FRCS, RAMC, Surgical Specialist

Capt T Yasin

MB, ChB, RAMC, Surgical SHO

\section{Lt Col D S Jackson}

FRCS, RAMC, Consultant Surgeon

RAM College, Millbank London

\section{Introduction}

This paper documents a terrorist incident when two British soldiers were shot by the Provisional IRA. Their first and second line management is described, and the lessons learnt from the incident are discussed.

\section{The Incident}

Two off-duty soldiers were ambushed in a street by three men in a car, who fired upon them at point blank range with a sustained burst from an automatic weapon and spaced shots from a handgun, at least 25 rounds being fired (Fig 1). Both soldiers collapsed and the terrorists escaped. The weapons have since been identified as a Yugoslavian $7.62 \mathrm{~mm}$ Kalashnikov AK47 and a 0.38 inch revolver.

First aid was administered by troops from an adjacent barracks and an off-duty doctor. Resuscitation was initiated on the arrival of two civilian ambulances and a military ambulance, a civilian trauma surgeon, and the duty surgical registrar from a British Military Hospital, $(\mathrm{BMH})$ who had been despatched to assess the situation.

\section{Soldier A}

Soldier A sustained two high velocity gunshot wounds and one low velocity wound to his lower limbs (Fig 2). The entry wounds were proximal to each patella. On the right thigh there was a combination injury with a compound comminuted fracture of the shaft of the femur and a $12 \mathrm{~cm}$ defect in the femoral artery and vein, in addition to a very large soft tissue medial exit wound. On the left there was a large soft tissue exit wound in the popliteal fossa, fortunately without neurovascular damage.

A tourniquet was applied to the upper right thigh, and intravenous fluid replacement with dextran 40 was rapidly instituted via several large bore cannulae. Progressive loss of consciousness necessitated intubation and ventilation.

It was decided to transfer him to the British Military Hospital. The Emergency Services relayed this message to the Orderly Medical Officer at BMH, who co-

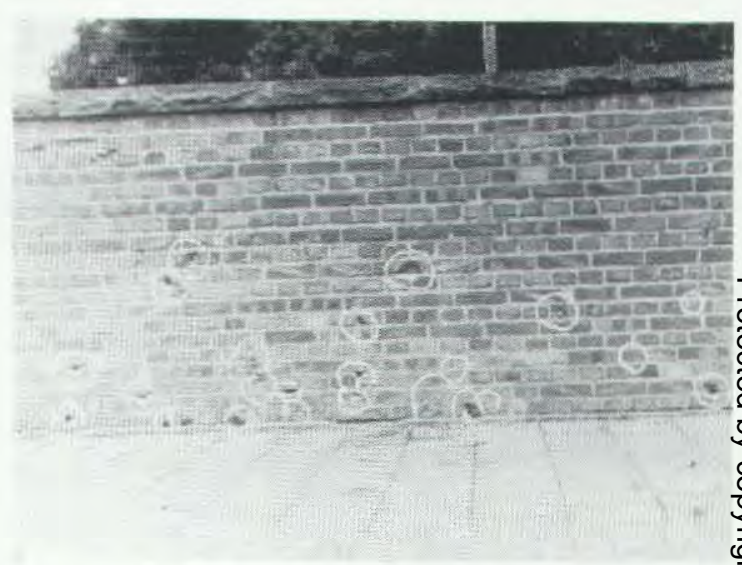

Fig 1. Wall with bullet holes.

ordinated the call-out of operating theatre staff, consultant surgeon, anaesthetists, pathology and X-ray staff. On arrival at BMH, Soldier A was transferred directly to the operating theatre.

Resuscitation was continued with the insertion of central venous lines, an arterial line, further peripheral lines and an urethral catheter. Three units of groupcompatible A-Positive blood were immediately transfused, the blood group having been ascertained from the soldier's identity card.

Despite these measures, resuscitation was ineffective, the soldier's blood pressure being unrecordable. The tourniquet had loosened, and was removed. Direct pressure over the wound and proximal femoral artery was only partially successful in controlling bleeding and immediate surgical exploration was undertaken. The proximal and distal ends of the divided femoral artery and vein were exposed and vascular clamps applied.

By now, one hour had elapsed from the time of the shooting. Once haemorrhage had been controlled, the patient was stabilised by further blood transfusion. 

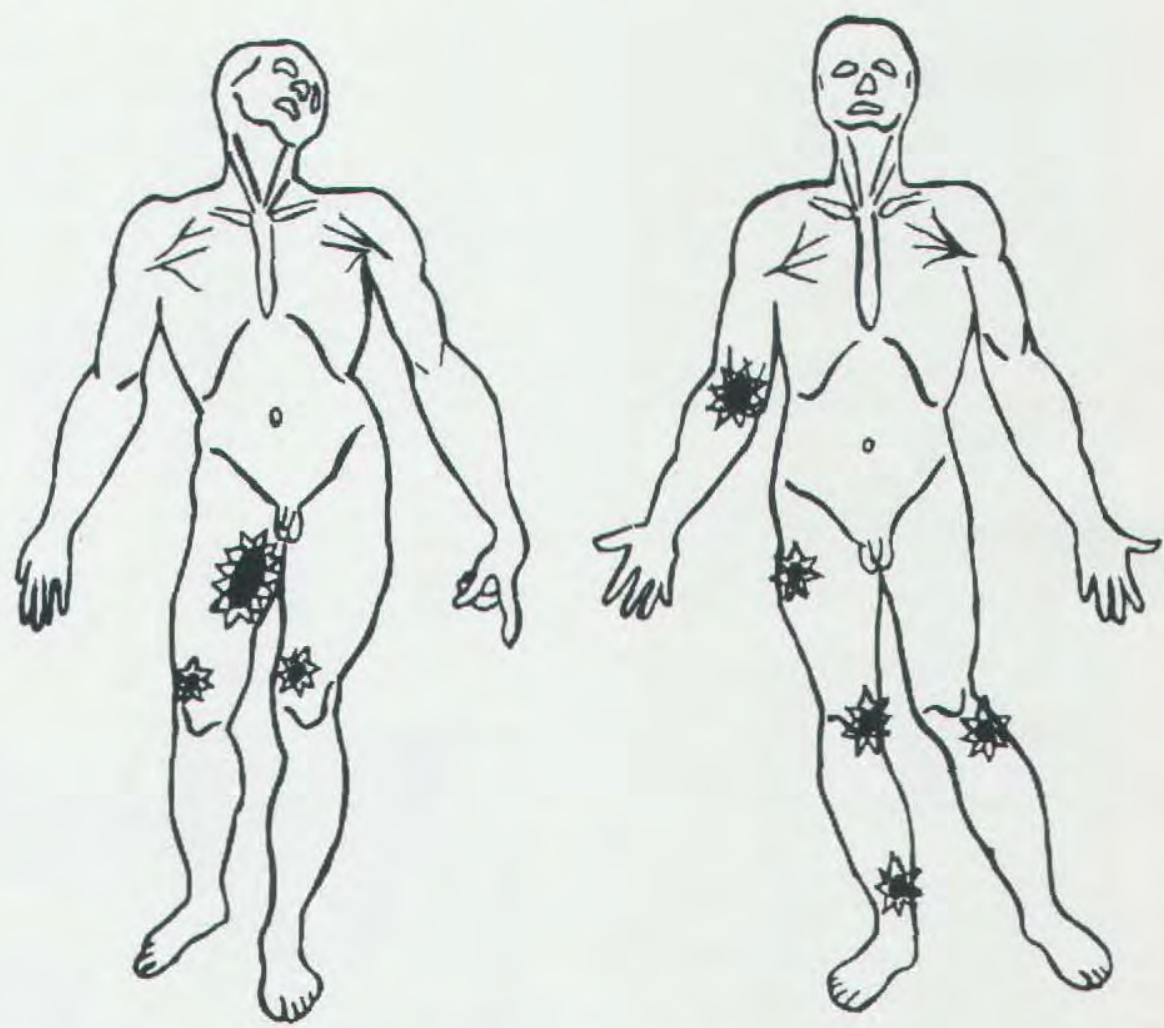

Fig 2. Wounds incurred by Soldier A (left) and Soldier B.

The subsequent operation consisted of the following stages:

a. Temporary restoration of circulation to the right leg with an improvised rubber shunt.

b. Cooling of the leg with ice packs.

c. Full heparinisation.

d. Fracture stabilisation with the "field fixator"*

e. Autogenous interposition saphenous vein grafting to the femoral artery and vein.

f. Definitive excision of all wounds.

g. Adequate fasciotomy.

h. Partial closure of the right thigh wound to protect the vein grafts.

i. All other wounds were left open and dressed.

During the operation, he received high dose intravenous antibiotic therapy with benzylpenicillin, gentamicin and metronidazole, as well as antitetanus immunoglobulin and tetanus toxoid booster.

$\mathrm{He}$ also received 18 units of blood (including 12 units of fresh platelet-rich blood) in addition to $2000 \mathrm{mls}$ of dextran 40 pre-operatively, $2000 \mathrm{mls}$ Haemaccel, and 7 units of fresh frozen plasma.

" Centrafix" external fixator, military pattern. Central Orthopaedics Ltd.
Serious intra-operative problems were hypovolaemi hypocalcaemia, hypokalaemia and metabolic acidosi $\mathbb{\Omega}$ Of note, the resultant hypotension adversely affecte blood flow through the grafts, which on occasion had to be maintained by intermittent manual compression.

He was extubated and awakened at the end of the operation, when he demonstrated that he could feel an move his right foot.

Post-Operative Progress. A large fracture-sit haematoma was evacuated under general anaesthetic 4 hours later. This haematoma had caused the femor vein graft to thrombose. However, further grafting wi not indicated at this stage, as limb swelling wo controlled by elevation.

An X-ray had demonstrated the presence of the low velocity round embedded near the right ischi요 tuberosity, but an attempt to retrieve it under this samp anaesthetic was unsuccessful (Fig 3).

Further transfusions resulted in soldier A receiving total of 27 units of blood and 9 units of fresh frozern plasma.

He was evacuated to another military hospital, s days after the shooting for further management. 


\section{Soldier B}

Soldier B received 5 high and low velocity gunshot wounds to the limbs (Fig 2), fortunately without incurring major vascular damage. He sustained a large soft tissue right upper thigh wound, as well as compound fractures of the right elbow (with disruption of the ulnar nerve), right medial femoral condyle, right tibia, and the neck of the left fibula (with division of the common peroneal nerve), with their associated soft tissue entry and exit wounds.

After initiation of intravenous fluid replacement with dextran 40 , he was transferred to the local civilian hospital for further resuscitation and surgery.

Initial surgical treatment involved:

a. High dose intravenous antibiotic therapy with a cephalosporin.

b. Fracture stabilisation of the right elbow and right leg with external fixators*

c. Excision of all wounds, with insertion of gentamicin beads.

d. Apposition of divided ulnar nerve.

e. Primary closure of the right elbow and knee, the other wounds being left open and dressed.

Post-Operative Progress. Soldier B subsequently developed compartment syndrome in both legs, necessitating extensive bilateral fasciotomy approximately 30 hours later. Despite this, the muscles of the left anterior tibial compartment underwent extensive necrosis, and were excised in two further operations at the civilian hospital, under the direct guidance and active involvement of the consultant surgeon from BMH, on the invitation of the civilian surgeons (Fig 4). He was ventilated for three days post injury, and transfused a total of 16 units of blood. Eight days after the shooting he was transferred to the BMH where he underwent partial delayed primary closure of most wounds prior to evacuation to another military hospital.

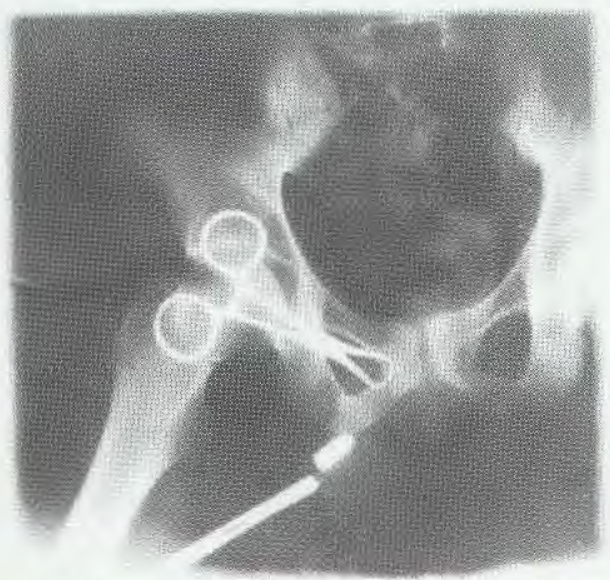

Fig 3. Low velocity round in 'Soldier A'.

\section{Discussion}

The facilities available for the resuscitation of the injured have improved dramatically since DominiqueJean Larrey established the rudiments of casualty care during the Napoleonic Wars'. Tremendous advances have been made in the First World War ${ }^{2}$ and the Second World $\mathrm{War}^{3}$, with further refinements in more recent conflicts ${ }^{4}$.

A minor criticism of the initial resuscitation of Soldier $\mathrm{A}$ is in the choice of dextran 40 as intravenous fluid replacement. Dextran interferes with subsequent crossmatching and a specimen of blood should be obtained for cross-matching prior to dextran infusion. Dextran also causes blood to congeal in the infusion tubing should blood be transfused subsequently. The use of polygeline ("Haemaccel"), 4\% gelatin in saline ("Gelofusin"), or human albumin solution would prevent these complications. When it becomes available blood is the fluid of choice for the replacement of blood losses.

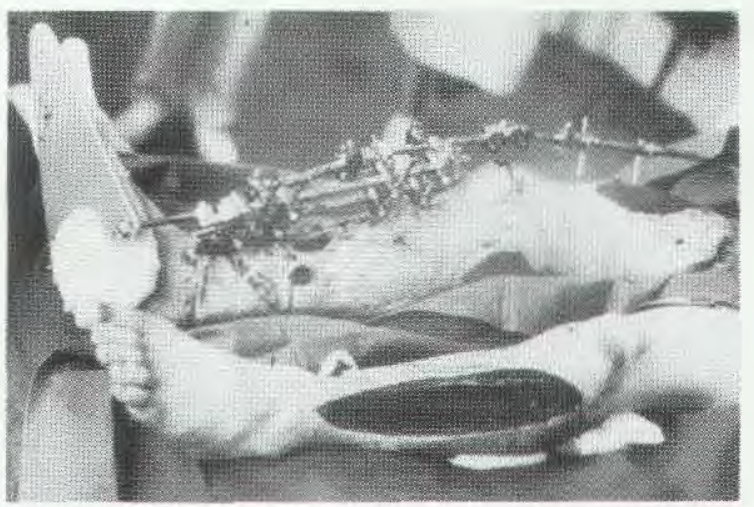

Fig 4. AO-Synthes external fixator and excision of left anterior tibial compartment.

The use of a tourniquet is a controversial but life saving measure. We endorse the statement in the "Field Surgery Pocket Book": "Tourniquets are rarely required for the control of bleeding and should only be used when all other methods fail, the severity of the haemorrhage is considered to be a danger to life and the risk of loss of the limb concerned is accepted. Correctly applied, a tourniquet will save life". However, once applied a tourniquet should be constantly supervised to maintain its effectiveness. Unfortunately during the transfer of Soldier A the tourniquet slackened and became ineffective. In fact by causing venous congestion such a tourniquet may even increase blood loss.

In some cases haemorrhage will not be controlled by "First Aid" measures of direct pressure to the bleeding point, pressure over proximal pulses or a tourniquet, as demonstrated in the case of Soldier A. Surgical exploration and control of bleeding points is a necessary part of resuscitation and should not be postponed while attempts to "stabilise" the patient are failing'. 
The axiom that correct surgical management is dependent on a knowledge of the cause and mechanism of disease is equally valid when considering traumatic injuries. The successful management of missile wounds, be they sustained through conventional or terrorist activities, requires knowledge of their pathophysiology and the ballistics of modern weaponry. This is especially true when considering the destructive effects of high velocity missile wounds ${ }^{7}$.

The principles of such "military surgery" are summarised as follows:

Through a generous incision all damaged skin, deep fascia, fat and muscle are excised, foreign material removed and haemostasis achieved. Compartmental decompression through adequate fasciotomies is necessary to prevent post-operative oedema prejudicing blood supply. Wounds should be left open and dressed, followed by subsequent wound reinspection and delayed primary closure $e^{4,5}$

The high mortality associated with major vascular damage is demonstrated in the report of the Hungerford shooting incident ${ }^{8}$ when three of the four patients sustaining such injuries died. The surgery of combination limb wounds requires the immediate control of haemorrhage, the restoration of circulation and the stabilisation of associated fractures.

After major vascular damage from high velocity missiles it will rarely be possible to restore circulation by end to end anastomosis. Autogenous interposition vein grafting will usually be necessary?

This is time consuming and the temporary restoration of circulation via a shunt is a well established procedure $^{9,10,11}$. This allows immediate reperfusion of the limb distal to the injury and reduces ischaemic damage. In Soldier A a temporary shunt was inserted within ten minutes of controlling the haemorrhage with vascular clamps, i.e. within seventy minutes of the shooting. In this case shunting was achieved by the improvised use of a rubber tube but purpose-designed vascular shunts, such as the "Brener" or "Javid" shunts*, are recommended.

Clearly such shunts need to be used with due consideration to the period of limb ischaemia, since the reperfusion of an ischaemic limb with release of toxic metabolites may lead to further circulatory collapse in a patient who is already hypovolaemic. Four to six hours ischaemic time would appear to be the limit".

When considering the management of injuries sustained in a terrorist incident in an urban "peacetime" environment one must be cautious in extrapolating results to a war-time scenario ${ }^{9}$. We believe however, that temporary vascular shunting may have a role in the advanced surgical management of casualties in any future major conventional conflict. Many problems can be envisaged and much research would be needed to establish whether temporary shunting is a viable option in war. However, a preliminary investigation could be

'Bard commenced on the basis of potential financial saving alone if one considers the cost of a shunt against the caz to the state of a permanently disabled serviceman. Ths may ultimately lead to vascular shunts forming part $₫$ the armamentarium of a field surgical team.

Associated fractures should subsequently stabilised by external fixation, and the Centrafix "fie? fixator" is ideally suited to this task by being both quif and simple to apply and it provides stable fixation (F 5).

The presence of an experienced surgeon from the British Military Hospital at the incident scene initiate्⿱一 the necessary liaison between the military and civilia medical services. Where logistically possible nक recommend the deployment of such a surgeon to maj $\vec{\varnothing}$ incidents such as this. His knowledge of the capabilitie and limitations of the military hospital will assist th coordination of casualty evacuation. He should be direct radio communication with the military hospital notify them of the number of casualties, their injuri and disposal. This recommendation is backed up by thes report of the Royal College of Surgeons of England oi "The Management of Patients with Major Injuries N which emphasises that "radio communication betwee\& those dealing with the patient at the site of the accideno and those preparing to receive the patient in hospial should be of the highest quality" ${ }^{\text {"12. }}$. This highligh" deficiency in the present military ambulance equipn熔 scales, as was evident in the case of Soldier A, for 9 military ambulance had no radio, and messages tori६ $\mathrm{BMH}$ had to be relayed by the Emergency Services. 0

When firearms are used in an urban setting it is li that civilian hospitals will receive patients with te severe and specialised injuries and some civi surgeons will not have had experience in t/\% management of these wounds. Perhaps it behoves us $\frac{\mathbb{R}}{\mathbb{a}}$ military surgeons to offer our expertise and becom actively involved early under these circumstance rather than await a call for assistance as happened in the case of Soldier B, in whom the development of the tibie compartment syndrome might have been anticipated.

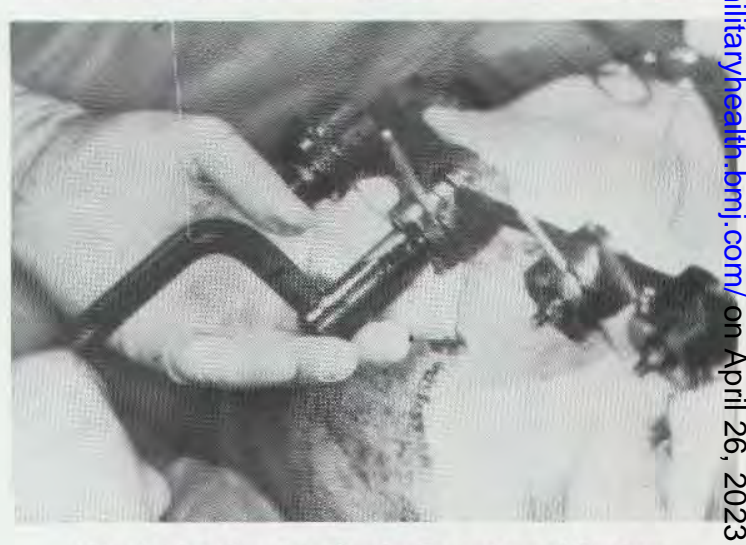

Fig 5. 'Soldier A': Centrafix external fixator. 


\section{Conclusion}

This paper stresses the need to remember the tried and proven principles of military surgery. That our civilian counterparts are not always so conversant in these principles highlights the need for the integration of "military" surgeons into a "civilian" trauma system.

The converse is also true and military surgeons need to be responsive to the developments, such as vascular shunting, occurring in civilian trauma centres. Such cross-fertilisation of ideas will improve the care of the wounded.

\section{REFERENCES}

1. Memoirs of Military Surgery, Larry D J, Paris 1814.

2. Official History of The War (1914-18). Medical Services: Surgery of The War, Vols I and II.

3. Stammers F A R. War Injuries of the Extremities and Their Treatment in Forward Areas. BrJ Surg; 1948, 2: 274 290 .

4. Surgery for Victims of War. Dufour D, Kroman Jensen S and Owen-Smith M S. Geneva. The International Committee of the Red Cross, 1988.
5. Field Surgery Pocket Book. Kirby N G and Blackburn G. London: HMSO, 1981.

6. JACKSON D S etal. The Falklands War: Army Field Surgical Experience. Ann R Coll Surg Engl 1983; 65: 281-285.

7. High Velocity Missile Wounds. Owen-Smith MS, London: Arnold, 1981 .

8. Broome G, et al. The Hungerford Shooting Incident. Injury 1988; 19: 313-317.

9. AIRES A B and BARRos D'SA. Management of Vascular Injuries of Civil Strife. Injury 1982; 14: 51-57.

10. Eger M, et al. The use of a temporary shunt in the management of arterial vascular injuries. Surg Gynecol Obstet 1971: 131: 67-70.

11. SZuChMACHER $P$ and Freed J. Immediate Revascularisation of the popliteal Artery and Vein: Report of a Case. J Trauma 1978; 18: 142-144.

12. Royal College of Surgeons of England. Commission on the Provision of Surgical Services 1988. Report of the Working Party on The Management of Patients with Major Injuries'.

\section{RAMC MUNIMENT ROOM COLLECTION AND MEDICAL LIBRARY}

It is notified for the information of all readers that The RAMC Muniment collection and those books of Historical Value, plus those Post-1850 Collection of Medical Text Books, previously held at the Royal Army Medical College Library in Millbank are now located at the Wellcome Institute for the History of Medicine in Euston Road, London. These collections remain the property of the RAMC and are available for research and other purposes. The collections have been catalogued and copies of the catalogue are to be available at the RAMC Historical Museum, the Royal Army Medical College Library and the Wellcome Institute. Enquiries in person, or in writing should be made to:

The Wellcome Institute for the History of Medicine 200, Euston Road

London

NW1 2BP Telephone 071-387-4477 Ext 3244/3350 